\title{
DEVELOPMENT OF ALGORITHMIC MODELS FOR RESEARCH OF RELIABILITY PARAMETERS OF TROLLEYBUS TRACTION ELECTRIC MOTORS IN THE OPERATION PROCESS
}

\author{
Vyacheslav Shavkun ${ }^{1}$ \\ vm.shavkun@gmail.com \\ Tatyana Pavlenko ${ }^{1}$ \\ tpavlenkoskp@gmail.com \\ Olha Kozlova ${ }^{1}$ \\ Olha.Kozlova@kname.edu.ua \\ ${ }^{1}$ Department of Electric Transport \\ National University of Urban Economy in Kharkiv \\ 17 Marshala Bazhanov str., Kharkiv, Ukraine, 61002
}

\begin{abstract}
The analysis of the reliability parameters of traction engines during the operation of trolleybuses in different modes is done. The presented groups of operational factors are lead to the emergence of censored samples. The methods of express analysis of engine reliability using technical diagnostic tools are determined. A block diagram of an algorithmic model for studying the reliability parameters of traction electric motors of trolleybuses during operation has been developed. It allows at any time to evaluate the influence of operational factors on the reliability indicators of traction electric engines and to more clearly and reasonably assign organizational, technical and preventive measures.

It has been established that the effective and reliable operation of urban electric transport, in particular trolleybuses, depends on the reliability of individual components and assemblies of rolling stock, as well as on the quality and timely control of their parameters during operation.

In practice, it has been proved that failure of traction electric motors (TEM) of trolleybuses leads to significant material losses at electric transport enterprises. And one of the main parameters of reliability of traction electric motors of trolleybuses is the reliability of operation during operation.

Based on the research results, practical recommendations are developed on the rational choice of diagnostic parameters. Their implementation at electric transport enterprises will increase the reliability of traction electric motors as a whole up to $10 \%$.

The developed methodology allows the study (assessment) of the reliability parameters of any type of traction engine of a trolley during operation.

Keywords: traction electric motor, reliability, distribution law, statistical data, operational factors, mathematical model, calculation algorithm.
\end{abstract}

DOI: $10.21303 / 2461-4262.2020 .001174$

\section{Introduction}

One of the common types of urban electric transport is a trolleybus, which has many advantages compared to shuttle buses and trams. During the operation of trolleybuses, the electric and mechanical load falls on traction electric motors (TEM), on which the further effective operation of the trolleybus on the routes of the city depends [1].

The object of research is traction electric motors used in urban electric transport. They are one of the main units that ensure the efficiency of the electric drive and rolling stock as a whole. Therefore, the task of studying (evaluating) the reliability parameters of TEM during operation in order to increase the operability of rolling stock as a whole indicates the relevance of this issue. 
Currently, new development and implementation of innovative technologies for more efficient use of known equipment, its modernization, increase reliability and increase the resource of work are necessary [1].

To determine the effective operation of the trolleybus on the line, modern methods for assessing the reliability of traction electric motors are used, which allow obtaining adequate characteristics taking into account the properties of the structure, the functional relationships of parts and assemblies.

In the direction of investigating the reliability parameters of TEM, methods are used that diagnose the parameters and characteristics [2-4].

For example, in [5-8], research methods and parameter estimation of asynchronous motors during their operation are reflected. But such methods are not universal and do not take into account the number of failures or their probability during the operation of traction electric motors of trolleybuses.

To assess the reliability parameters and characteristics of traction electric motors, analytical and statistical methods are used, due to which the relationship between the parameters of the engine elements during loading is determined [9-11]. The use of these methods is also shown in [12-14]. The disadvantage of such technical solutions is the lack of a comprehensive assessment of the operational reliability of traction electric motors, namely, the load conditions and strength parameters of elements that vary over time are not taken into account. Thus, it is impossible to fix the failure parameters of parts and components of traction electric motors, which indicates comprehensive studies that are not fully used.

Reliability problems of electric machines are also dealt with by foreign-scientists. So, for example, in $[15,16]$ a method is presented that requires only idle testing to obtain the parameters of an induction machine.

In the article [17], the influence of thermal processes on the structural elements of the electric motor is analyzed and the factors determining the residual life of the traction motor are identified. The presented method for predicting the residual life of asynchronous traction electric motors based on information on their thermal state does not provide complete information about the technical condition of the object.

A theoretical rationale for the development of energy-efficient electric drives [18, 19] for technological installations based on intelligent control and monitoring systems is proposed.

Issues of identification, diagnosis and prediction of malfunctions in electric drives that increase the reliability of electric vehicles are considered in [20,21]. The methods and developments proposed in the work are not able to reproduce the nature of the occurrence of failures and to predict their consequences from the impact of such operational factors: switching quality, supply voltage, current, speed and mode of movement, weather and climate conditions, etc.

Thus, the analysis of scientific research carried out above showed that the problems of increasing the efficiency and extending the life of TEM by studying (evaluating) their reliability parameters during the operation of trolleybuses are, at the moment, practically unresolved and relevant.

So, the topic of work and questions are considered relevant. New technical solutions for improving research methods, evaluating the reliability parameters of traction electric motors of trolleybuses will reduce energy and resource costs during operation and repair.

The aim of research is development of an algorithmic model for the study (assessment) of the reliability parameters of traction electric motors of trolleybuses during operation.

Accordingly, regarding the aim of research, the following tasks are defined:

- to analyze the reliability parameters of traction electric motors of trolleybuses and determine the laws of distribution of their failures;

- to develop an algorithmic model for the study (assessment) of the reliability parameters of traction electric motors of trolleybuses during operation. 


\section{Materials and methods for analyzing the reliability parameters of traction electric motors of trolleybuses and the development of an algorithmic model}

When analyzing the results of observations, the choice of the law of distribution of the operating hours of traction electric motors to failure, based on the study of the physical laws of failure, is almost impossible. Then statistical methods become fundamental in solving this problem.

But under operating conditions, statistics on failures of traction electric motors, as a rule, do not provide complete information and have a high degree of uncertainty. From the point of view of mathematical statistics, the result of the controlled operation of traction electric motors is heterogeneous information with random values. This is due to the fact that during the operation of traction electric motors or the study of controlled groups, electric motors with random changes in the intensity of use get into it. Such results inevitably lead to a random dispersion of operating time.

Given the changes in determining the reliability characteristics of traction electric motors, it is necessary to carry out on the basis of specific samples. This method is called the censored sampling method. From this point of view, it is necessary to take into account the following factors leading to the emergence of censored samples:

- different times of the beginning and end of operation of traction electric motors;

- removal from testing or operation of traction electric motors in case of organizational reasons or due to failures of components;

- transition of traction motors from one operating mode to another during operation;

- need to assess reliability before the failure of all tested traction electric motors;

- periodic monitoring of traction electric motors, which leads to the appearance of reliability information in the form of observation intervals (grouping of information).

Thus, censorship of samples covers many situations that arise when operating traction electric motors. By virtue of the indicated groups of operational factors, determining the reliability parameters of traction electric motors during operation is a difficult task.

\section{Research results}

Using statistical methods, a method for estimating reliability parameters has been developed in practice, which is implemented as an algorithmic model. A block diagram of an algorithmic model for studying the reliability parameters of traction electric motors of trolleybuses during operation is shown in Fig. 1.

To evaluate the reliability parameters of traction electric motors with small and censored samples on the basis of the utility company "Trolleybus depot No. 3" in Kharkiv, a mathematical model is developed that allows approximating the distribution function for the failure of traction electric motors [12-14].

In block 1, the matrix of operating time from two columns and $\mathrm{N}$ rows is filled. When filling in the matrix, it is also necessary to place the elements of the indicator array in accordance with the type of operating time. If the corresponding operating time is the operating time of the object to failure, then " 1 " is not realized the moment of censorship. For the time to stop monitoring (censor the time), the value " 0 " is accepted.

In block 2, according to the operating time to failures and censorship of the samples, a statistical estimate of the cumulative failure rate $\lambda\left(t_{i}\right)$ is calculated and a sample conditional distribution density around a random running time $t_{j}$ is determined:

$$
\lambda\left(t_{i}\right)=\sum_{i=1}^{j} \frac{r_{i}}{N-\sum_{i=0}^{j=1} r_{i}-n_{i}}
$$

where $\lambda\left(t_{i}\right)$ - failure rate; $r_{i}$ - TEM technical resource; $n_{i}$ - number of motor failures; $N$ - number of rows of the operating time matrix. 


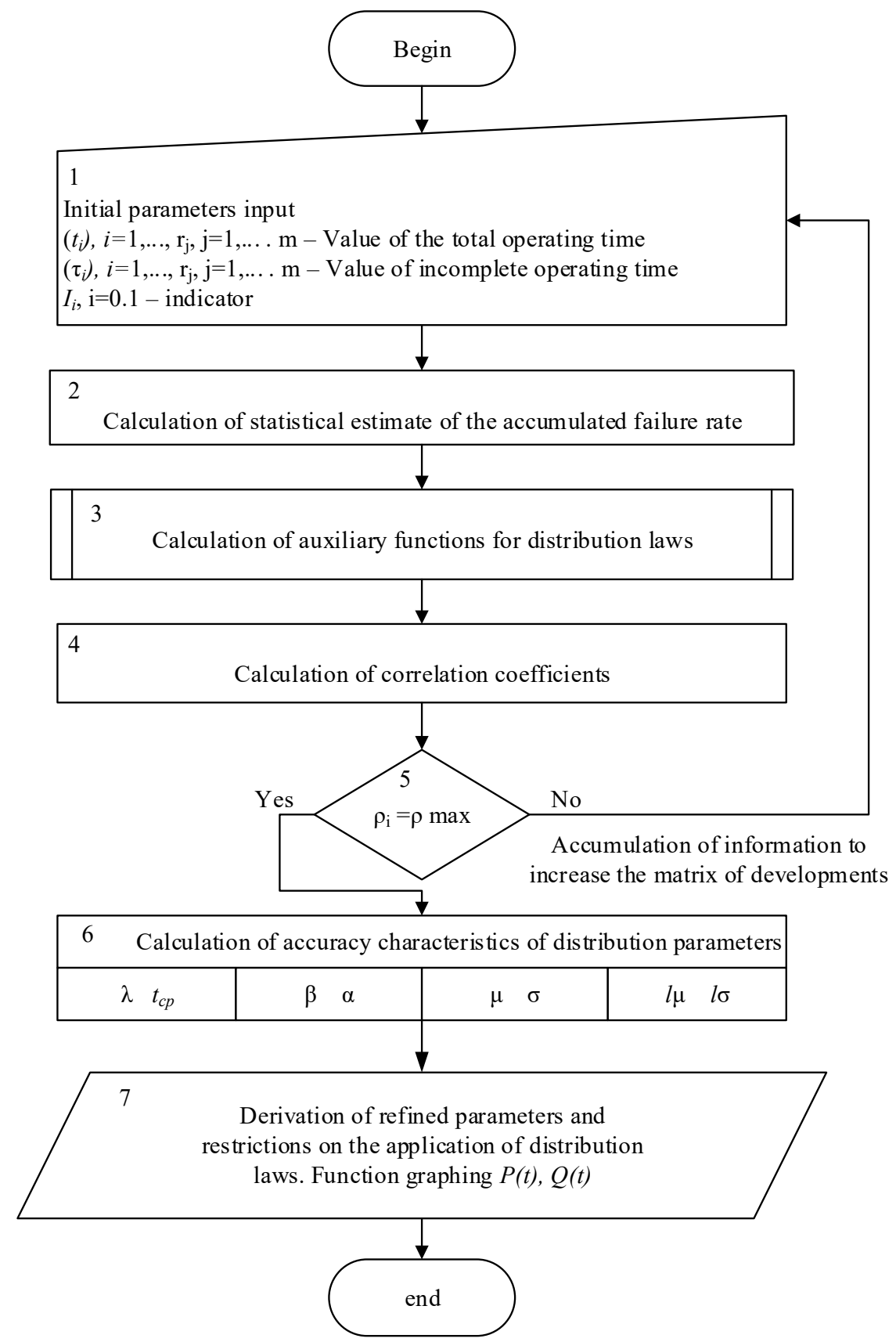

Fig. 1. A block diagram of an algorithmic model for studying the reliability parameters of traction electric motors of trolleybuses during operation

In block 3 , the auxiliary functions $\psi_{i}, g_{j}$ are calculated for the following distribution laws: exponential, Weibull, normal, and log-normal:

$$
\psi_{i} /\left|t_{i}\right| \cdot \ln \left(\left|t_{i}\right|\right) \cdot U_{t_{i}}\left(F_{N}\right)
$$

where $\psi_{\mathrm{i}}$ - an auxiliary function; $t_{\mathrm{i}}$ - operating hours of the $i$-th electric motor; $U_{t_{i}}\left(F_{N}\right)$ distribution function of the average time between failures.

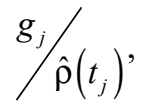




$$
\ln (\hat{\rho}) ;\left|t_{j}\right| ; \ln \left(\left|t_{j}\right|\right)
$$

where $g_{j}$ - auxiliary function; $t_{j}$ - random operating time;

In block 4, a sample correlation coefficient $\rho$ is calculated for each distribution law of auxiliary functions:

$$
\rho=\frac{\sum \psi_{i} g_{j}-\frac{1}{N-k_{0}}\left(\sum \psi_{i}\right)\left(\sum g_{j}\right)}{\sqrt{\left[\sum \psi_{i}^{2}-\frac{1}{N-k_{0}}\left(\sum \psi_{i}\right)^{2}\right]\left[\sum g_{j}^{2}-\frac{1}{N-k_{0}}\left(\sum g_{j}\right)^{2}\right]}}
$$

where $\rho$ - sample correlation coefficient; $k_{0}$ - failure coefficient of electric motor elements.

Block 5 contains an analysis of the sample correlation coefficient $\rho$. Its maximum value $\left(\rho_{\max }\right)$ corresponds to the most probable distribution of operating hours to failure of the considered group of traction electric motors.

The result is considered probable when $\rho>0.95$. If this condition is not met, the initial operating time matrix should be considered incorrect, i. e., the dimension of the matrix does not allow solving the problem of evaluating the reliability parameters. In this case, information must be accumulated to increase the dimension of the operating time matrix (database, statistics on failures).

In block 6, the values of the laws of distribution are refined and the boundaries of their application are determined. The accuracy characteristics of the following failure distribution parameters are calculated according to the exponential law: $\lambda$ - failure rate, $t_{a v}$ - average time between failures; according to Weibull law: $\alpha$ - failure rate; $\beta$ - significance level of failures; according to the normal law: $\mu$ - failure flow rate, $\sigma$ - standard deviation of time between failures; according to the logarithmically normal law: $l \mu$ - failure flow rate, $l \sigma$ - standard deviation of time between failures.

Block 7 serves to derive the accuracy of the characteristics of the failure distribution parameters of traction electric motors and derive the following dependencies: $P(t)$ - probability of failure-free operation, $Q(t)$ - probability of failure.

According to the statistical data of the operating time to failure and censorship of the samples, the accumulated failure rate $\lambda\left(t_{i}\right)$ is calculated according to block 2 .

Sample correlation coefficients are determined for each distribution law (block 4). The maximum value of the coefficients corresponds to the most probable distribution of operating hours before the TEM failure. The calculation results are shown in Table 1.

Table 1

Selected correlation coefficients

\begin{tabular}{ccccc}
\hline \multirow{2}{*}{$\begin{array}{c}\text { Correlation } \\
\text { coefficients }\end{array}$} & Exponential $\boldsymbol{P}_{\mathbf{1}}(\boldsymbol{t})$ & Weibull $\boldsymbol{P}_{\mathbf{2}}(\boldsymbol{t})$ & Normal $\boldsymbol{P}_{\mathbf{3}}(\boldsymbol{t})$ & Log-normal $\boldsymbol{P}_{\mathbf{4}}(\boldsymbol{t})$ \\
\cline { 2 - 5 } & 0,977537 & 0,923269 & 0,901719 & 0,895867
\end{tabular}

The calculation makes it possible to establish the dependencies for assessing the reliability of average indicators. Average operating time to failure $\left(t_{a v}\right)$ of traction electric motors is:

$$
t_{a v}=\frac{\sum_{i=1}^{N} t_{i}}{\sum_{j=1}^{N} t_{j}}=1,213, \mathrm{~h}
$$

where $t_{j}$ - random operating time. 
The failure rate $(\lambda)$ is respectively:

$$
\lambda=\frac{1}{t_{a v}}=0.000824 \frac{1}{\mathrm{~h}},
$$

where $t_{a v}$ - average operating time to TEM failure.

According to the calculation data, the dependences of the reliability functions of traction electric motors are presented (Fig. 2-4) for various distribution laws.

Fig. 2 shows the graphs of the reliability functions for the exponential distribution law $P_{1}(t)$ and the Weibull law $P_{2}(t)$.

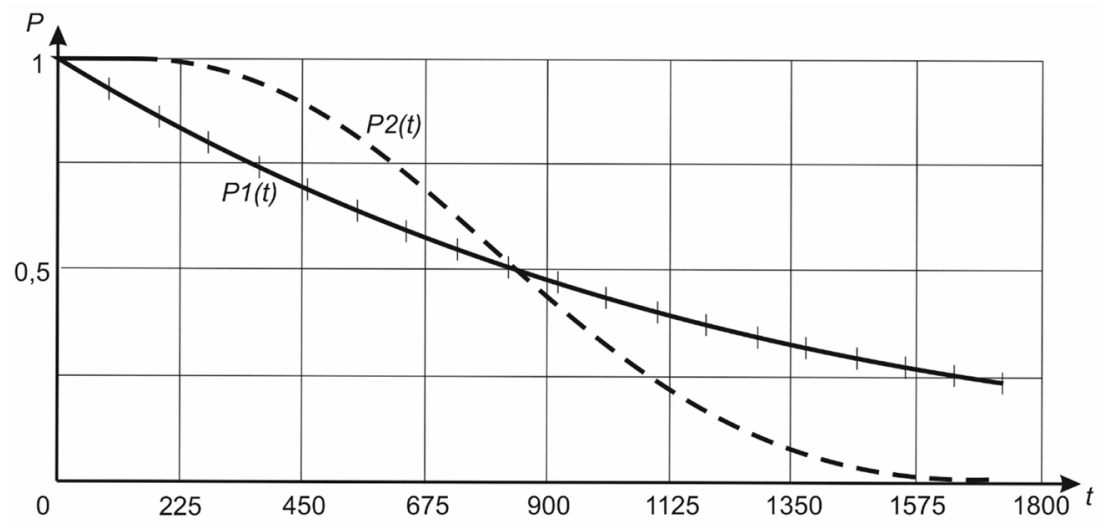

Fig. 2. Graphs of reliability functions for the exponential distribution law $P_{1}(t)$ and Weibull law $P_{2}(t)$

An analysis of the research results confirms that the nature of the occurrence of failures and their consequences depends on the complexity of the structure, the functional relationships of the TEM elements and the effects of the following operating factors: switching quality, supply voltage, current, speed and driving modes, and weather and climate conditions, and the like.

\section{Discussion of results}

Based on the research results and calculations, it is found that the most accurately describes the processes of the dependence of the probability of failure-free operation of traction electric motors on their operating time (running hours) the exponential distribution law $P_{1}(t)$.

Fig. 3 shows the graphs of the reliability functions for the normal distribution law $P_{3}(t)$ and the logarithmically normal law $P_{4}(t)$.

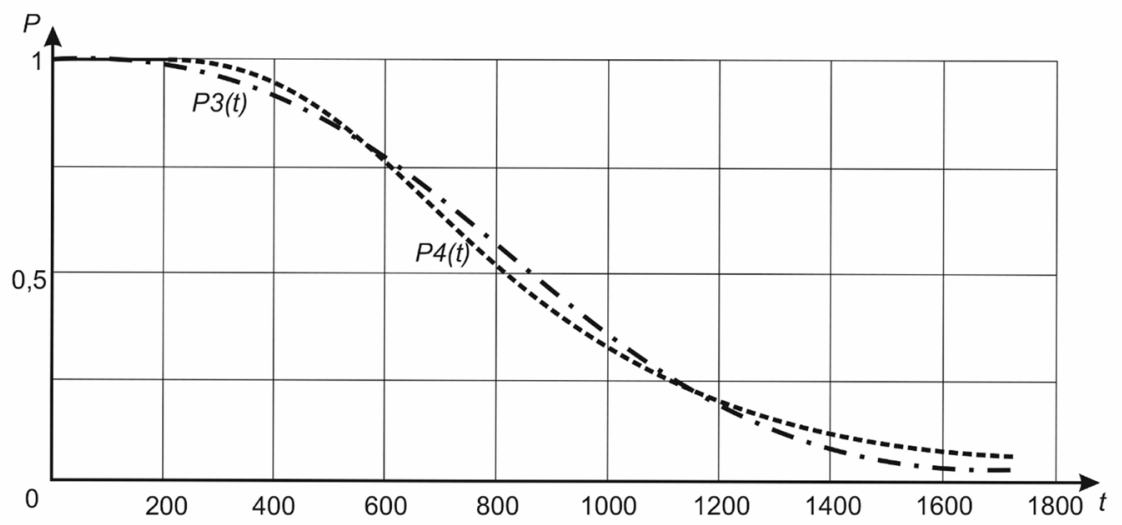

Fig. 3. Graphs of reliability functions for the normal distribution law $P_{3}(t)$ and the logarithmically normal law $P_{4}(t)$ 
The obtained dependences make it possible to select the initial data for studying the reliability parameters of the trolleybuses' TEM during operation. The dependence of the reliability and failure functions (Fig. 4) analyzes the set of TEM developments of the rolling stock of trolleybuses, which is characterized by an increasing function of the probability of failures $Q(t)$, which may indicate a revealed trend of deterioration of their technical condition.

As a research result, it is found that the exponential distribution law $P_{1}(t)$ of the failure-free operation time of traction electric motors allows to analyze a number of causes of failures during the operation of trolleybuses. This law is also characteristic of trolleybuses, on which errors are made during the operation and repair of traction electric motors [13, 14$]$.

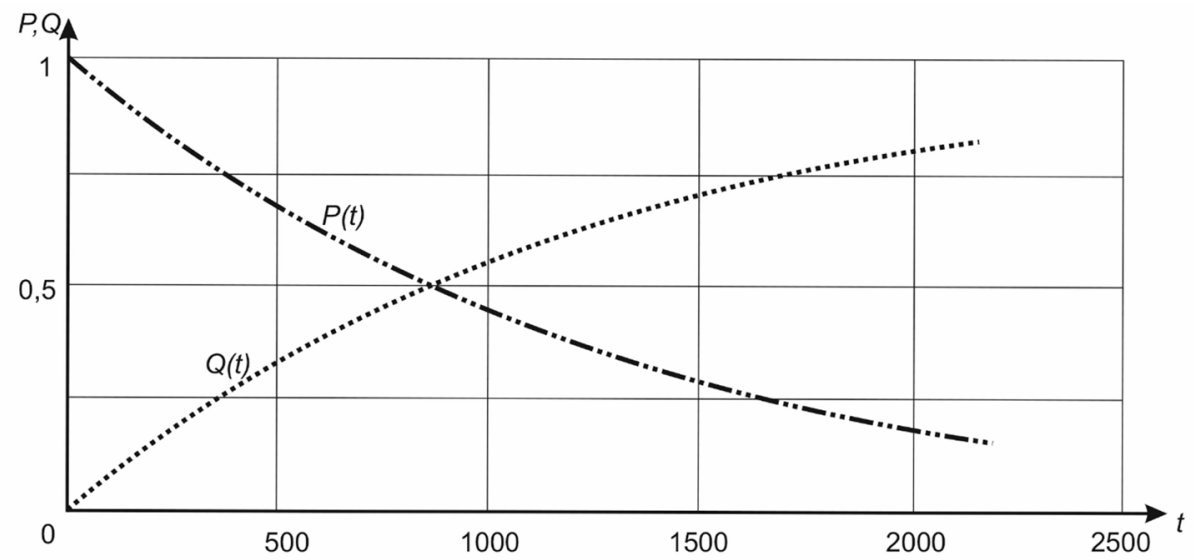

Fig. 4. Dependence of the function of reliability and failures

For example, for TEM and all active mechanical elements of the electric drive, a random sharply variable cyclic load mode is characteristic. As a result, this leads to the failure of the mechanical elements of the traction electric motors due to the intense accumulation of damage, as well as to thermal and vibromechanical drifts of the insulation of the windings.

If the exponential distribution law is characterized by a constant failure rate, then this condition should be taken into account when developing a system of scheduled preventive repairs.

\section{Conclusions}

In accordance with the assignment, an analysis of the reliability parameters of the traction electric motors of trolleybuses shows that the average operating time to failure is $t_{a v}=1213$ hours, and the failure rate is $\lambda=0.0008241$ /hour.

To increase the TEM effective operation, a study of reliability parameters is carried out using statistical methods. The laws of the distribution of failures of traction electric motors are determined and sample correlation coefficients for each law are calculated.

Taking into account the influence of operational factors, an algorithmic model has been developed to study (evaluate) the reliability parameters of traction electric motors of trolleybuses during operation, which is universal for all types of TEMs for DC motors. The application of the algorithmic model in practice will help to increase the reliability parameters and extend the TEM life during the operation of trolleybuses. The model shown allows to determine the time for a simple trolleybus from the causes of TEM failures, unplanned repairs, and the like. This will allow operating enterprises to increase the performance of trolleybuses on the routes of the city.

\section{References}

[1] Yatsun, M. A., Yatsun, A. M. (2010). Operations and diagnostics of electric machines and apparatuses. Lviv: «Lvivska politekhnika», 228.

[2] Shavkun, V. M., Pevnaya, A. A., Uvarov, O. B. (2015). Investigation of the influence of operational factors on the loading parameters of power electrical equipment of trolleybuses. Simvol nauki, 11, 64-67. 
[3] Daleka, V. Kh., Budnychenko, V. B., Karpushyn, E. I., Kovalenko, V. I. (2014). Technical Operation of Urban Electric Transport. Kharkiv: KhNUMH, 235.

[4] Shavkun, V. (2010). On the issue of increasing the reliability of traction electric motors and resource conservation on the rolling stock of urban electric transport. Komunalne hospodarstvo mist, 97, 272-278.

[5] Castaldi, P., Tilli, A. (2005). Parameter estimation of induction motor at standstill with magnetic flux monitoring. IEEE Transactions on Control Systems Technology, 13 (3), 386-400. doi: https://doi.org/10.1109/tcst.2004.841643

[6] Peresada, S., Montanari, M., Till, A., Bolotnikov, A. (2007). A speed-sensorless indirect field-oriented control for induction motor: theoreticfl result and experimental evaluation. Zbirnyk naukovykh prats Dniprodzerzhynskoho derzhavnoho tekhnichnoho universytetu (tekhnichni nauky). Problemy avtomatyzovanoho elektropryvoda. Teoriya i praktyka, 60-65.

[7] Douglas, H., Pillay, P., Ziarani, A. (2003). Detection of broken rotor bars in induction motors using wavelet analysis. IEEE InternationalElectric Machines and Drives Conference, 2003. IEMDC'03. doi: https://doi.org/10.1109/iemdc.2003.1210345

[8] Stephan, J., Bodson, M., Chiasson, J. (1994). Real-time estimation of the parameters and fluxes of induction motors. IEEE Transactions on Industry Applications, 30 (3), 746-759. doi: https://doi.org/10.1109/28.293725

[9] Lukianov, S., Karandaev, A., Sarvarov, A. et. al. (2014). Development and implementation of intelektualni systems of diagnosing the technical condition elektrooborudovaniya. Bulletin of Magnitogorsk state technical University. Named after G. I. Nosova, 1 (45), 129-134.

[10] Mehala, N., Dahiya, R. (2007). Motor current signature analysis and its applications in induction motor fault diagnosis. International journal of systems applications, engineering \& development, 2 (1), 29-35.

[11] Sinchuk, O. M., Sushko, D. L. (2003). To the problem of construction of a complex, continuous system of diagnostics of traction electric vehicles of rolling stock. Bulletin of the East-Ukrainian National University named after. V. Dal, 9 (67), $25-28$.

[12] Shavkun, V. (2014). Diagnostics of electric transport traction electric machines. Eastern-European Journal of Enterprise Technologies, 1 (7 (67)), 48-53. doi: https://doi.org/10.15587/1729-4061.2014.20196

[13] Pavlenko, T., Shavkun, V., Petrenko, A. (2017). Ways to improve operation reliability of traction electric motors of the rolling stock of electric transport. Eastern-European Journal of Enterprise Technologies, 5 (8 (89)), 22-30. doi: https://doi.org/ 10.15587/1729-4061.2017.112109

[14] Pavlenko, T. P., Shavkun, V. M., Scurihin, V. I., Lukashova, N. P. (2018). Methodology of determining the parameters of traction electric motor failures when operating trolleybuses. Science and Transport Progress. Bulletin of Dnipropetrovsk National University of Railway Transport, 4 (76), 47-59. doi: https://doi.org/10.15802/stp2018/140707

[15] Aminu, M., Ainah, P. K., Abana, M., Abu, U. A. (2018). Identification of induction machine parameters using only no-load test measurements. Nigerian Journal of Technology, 37 (3), 742. doi: https://doi.org/10.4314/njt.v37i3.25

[16] Kolcio, K., Fesq, L. (2016). Model-based off-nominal state isolation and detection system for autonomous fault management. 2016 IEEE Aerospace Conference. doi: https://doi.org/10.1109/aero.2016.7500793

[17] Dorokhina, E. S., Goldovskaya, A. A., Girnik, A. S. (2019). A Way to Predict the Residual Lifetime of Induction Traction Electric Motors. Journal of Machinery Manufacture and Reliability, 48 (4), 336-339. doi: https://doi.org/10.3103/s105261881904006x

[18] Loureiro, R., Benmoussa, S., Touati, Y., Merzouki, R., Ould Bouamama, B. (2014). Integration of Fault Diagnosis and Fault-Tolerant Control for Health Monitoring of a Class of MIMO Intelligent Autonomous Vehicles. IEEE Transactions on Vehicular Technology, 63 (1), 30-39. doi: https://doi.org/10.1109/tvt.2013.2274289

[19] Zaiets, N., Kondratenko, I. (2019). Development of an Intelligent System for Predicting the Reliability of Electric Motors. 2019 IEEE 39th International Conference on Electronics and Nanotechnology (ELNANO). doi: https://doi.org/10.1109/elnano. 2019.8783564

[20] Venkatesan, S., Manickavasagam, K., Tengenkai, N., Vijayalakshmi, N. (2019). Health monitoring and prognosis of electric vehicle motor using intelligent-digital twin. IET Electric Power Applications, 13 (9), 1328-1335. doi: https://oi.org/10.1049/ iet-epa.2018.5732

[21] Zou, Y., Kuruppu, S., He, J., Cao, B. (2019). Reliability Improvement of Power Inverters for Low-Speed High-Power Motor Drives. 2019 IEEE Applied Power Electronics Conference and Exposition (APEC). doi: https://doi.org/10.1109/apec. 2019.8721818

Received date 13.07.2019

Accepted date 21.02.2020

Published date 31.03.2020
(C) The Author(s) 2020

This is an open access article under the CC BY license (http://creativecommons.org/licenses/by/4.0). 